strychnine. The hairs were found to contain 8 per cent. of fat and 1 per cent. of strychnine. Liquid extracts were then prepared from these as above. 'The liquid extract prepared from the scraper seeds (C 1) contained 0.8 per cent. of fat and 1.16 per cent. of strychnine. 'Therefore the amount of alcohol (70 per cent.) required to extract three-fourths of the strychnine only removed about one-fifth of the fat. The liquid extract prepared from the hairs (C2) contained 1.72 per cent. of fat and 0.33 per cent. of strychnine. Therefore the amount of alcohol ( 70 per cent.) required to extract onethird of the strychnine removed one-fourth of the fat. There was, however, a source of error in this last experiment, as, the supply of liquid extract running short, the strychnine was determined on the residue left after the removal of the fat, and strychnine not being entirely insoluble in ether there was probably some loss of the alkaloid.

We intend to continue these experiments, but publish the results obtained so far now in the hope that other workers will contribute such facts and figures as have come to their notice. We think, however, that we are justified in drawing the following conclusions: (1) that the hairs of nux vomica contain proportionately much more fat and less strychnine than do the inner portions of the seeds; (2) that the fat is more readily removed by alcohol ( 70 per cent.) from the hairs than from the denser portions of the seed; and (3) it follows that the hairs can be rejected with advantage before making the liquid extract.

\section{THREE CASES OF SKIN DISEASE.}

By ROBERT SAUNDBY, M.D. EDIN., F.R.C.P. LoND.

PROFESSOR OF MEDICINE, UNIVERSITY OF BIRMIXGHAM; SENIOR PHY SICIAN TO THE BIRMINGHAM GEXERAL HOSPITAL, FTC.

THE three following cases of somewhat uncommon diseases of the skin occurred during the current year in patients under my charge at the Birmingham General Hospital.

CASE 1. Acute pemphigus in a butcher's boy resulting in recovery. - The patient, aged 14 years, was admitted into the General Hospital on March 3rd, 1904, complaining of an eruption on his skin, sore-throat, and headache of 11 days duration. His family and previous history were unimportant. Three weeks previously he cut his finger at his work; the wound did not heal and was poulticed by his mother. Eleven days previously, ten days after the wound to his finger, the patient felt too ill to go to work and a bullous eruption broke out, the first bleb being below the left eye. On admission his finger was practically healed but there was a small granulating surface still to be seen. The eruption covered the face and head and involved the mouth and tongue. His lips and tongue were so swollen that it was not possible to see exactly the distance to which the eruption extended to the back of the cavity. There was a similar eruption around the anus, but the epidermis had in places been rubbed off, leaving a raw ulcerated surface. 'The eruption on the face consisted of oval bullæ from a half to two-thirds of an inch in their longest diameter, containing sero-purulent fluid and surrounded by a pink areola; where the epidermis was detached there was a raw granulating surface. His temperature on admission was $100.4^{\circ} \mathrm{F}$. and his pulse was 84. His urine contained a haze of albumin. Examination of the blood was normal. 'There was no eosinophilia. Cultivations of the fluid from the blebs produced only the bacillus coli. His temperature became normal on the fourth day after admission and his general condition was quite satisfactory. The rash was treated by a dusting powder containing one part of boric acid, one part of glutol, and eight parts of kaolin ; but as after five days there seemed to be no change he was given in addition by the mouth five minims of liquor arsenicalis three times a day and on the 11th this was increased to ten minims. Improvement commenced at once and by March 25th he was nearly well. The albumin disappeared from his urine and he was discharged quite cured on April 5th.

During the last few years a good deal of attention has been drawn to a form of pemphigus which occurs in butchers or those handling animal tissues. Our knowledge of it is chiefly due to Pernet and Bulloch but the case under consideration differs from this classical description in certain respects: (1) the mildness of the constitutional disturbance (2) absence of the diplococcus described by Demme and confirmed by Bleibtrea and 13ulloch ; and (3) the good effect of arsenic. 'The case is of importance as tencing to modify the grave prognosis of these cases. It is evident that the infection is not always virulent.

CASE 2. Occupation rash ouused by biohromate of potrossium. -The patient, a man, aged 33 years, came to the ont-patient department on Jan. 12th, 1904, complaining of a skin eruption on both forearms. He had been under my care in December, 1901, suffering from phthisis and in February, 1902, was admitted into the hospital and underwent a course of treatment by Koch's tuberculin-R. As the result he gained nine pounds in weight, there was a diminution of all symptoms, and he had been able to work up to the time of his reappearance at the hospital. There was a marked family history of consumption, one brother and two uncles having died from that disease. Accorling to the notes taken during his former stiay in hospital the apices of both lungs were involved and tubercle bacilli were present. He was treated with injections of tuberculin- $R$, commencing with $=\frac{1}{0}$ th of a milligranme and increased until $20 \mathrm{milli}$ grammes were given. After his discharge he continued to attend for some time to receive injections. As these injections had been made chiefly in the forearm he suspected that the eruption of which he complained might have something to do with them. The eruption when seen consisted of round or oval elevated purplish-red patches with some slight scaliness. He was toll that the eruption "was probably due to something which he handled and on inquiry it was found that he was a warehouseman engaged in handling upholstery materials and on a future visit he brough to the hospital some scraps of cotton velvet which were examined by Dr. W. H. Wynn, pathologist to the hospital. Dr. Wynn found that the velvet contained potassium bichromate, alum, and a salt of iron and that the bichromate was present in sufficient quantities to account for the rash. The patient had not improved but he had not given up work and the eruption spread over his face, body, and lower extremities, so he was admitted into the General Hospital where the treatment consisted of cleanliness by means of baths and the application of boric acid ointment to the skin. Under these means he made a complete recovery and was discharged on March 2nd cured.

This is a very good example of a bichromate of potassium eruption. Successful treatment of occupation rashes depends entirely on a correct diagnosis; when that is made the rest is perfectly easy and merely involves the application of the principle causa sublata tollitur effectus. We are led to suspect an occupation rash when it commences upon the hands or forearms; in all such cases this possibility should be taken into account and no routine diagnosis of eczema accepted as satisfactory.

CASE 3. Orthostatic purpura.-The patient, a man, aged 43 years, was admitted into the General Hospital on Feb. 12th, 1904, complaining of swelling of the legs and a rash all over the lower extremities of two days' duration. There was no bistory in the family of tubercle or rheumatic fever. The patient said that he was well until 29 years of age when he suffered from enteric fever in Bengal; three or four years later he had intermittent malarial fever in Lower Burmah and the attacks continued until after his return home. Two years previously he had pleurisy and was ill in bed for a month. Since then he had always suffered from a cough and some few months after the attack of pleurisy he coughed up from a pint to one and a half pints of blood. During the last two years he had lost 3 stones 4 pounds; 18 months previously he began to suffer with pain in the back radiating around his thorax. On examination the patient looked pale and thin ; there was marked angular curvature of the spine, beginning at the eighth dorsal vertebra and involving the following two segments. There was dulness at both apices especially on the left side, while the right base behind was dull below the level of the seventh rib. Over the dull areas bronchial breathing and moist sounds could be heard. The swelling of the legs disappeared after his admission but both lower extremities were covered with a purpuric eruption extending up to the buttocks but most marked from the ankles to the knees. There was also a slight eruption of the same kind on the upper surface of the forearms. The liver and spleen were normal. The urine contained a trace of albumin. The blood was quite sterile. An attempt to support the spine by a Sayre's jacket failed as it made his back sore and the patient refused to allow another trial to be made. After resting in bed until the 29th the rash had entirely disappeared, so that he was allowed up for 
two and a half hours, with the result that the next day the eruption had returned and was as extensive as before. A week later the same result followed a similar experiment. By March 14th the spots had gone but as the jacket had to be taken off he could not be allowed to get up. He remained in hospital until March 19th when he left at his own request. The treatment, which seemed to have no effect, consisted of at first lemon juice, half-ounce doses taken in soda-water three times a day; secondly, ten-minim doses of turpentine three times a day; and lastly, 15 grains of calcium chloride in water three times a day. The effect of the last remedy is not known as the patient had to be kept in a recumbent position owing to the state of his spine.

'This is a well-marked case of orthostatic purpura, such as is commonly seen after acute rheumatism, where the eruption comes out as soon as the patient is allowed to get up and disappears when he resumes a horizontal position. It is apparently due to the state of the blood and usually passes off in a few weeks. The blood condition is not known. It might be suggested that the condition in this case was due to the lesion in the cord, the injury there setting up vaso-motor paralysis, but it seems unnecessary to adopt such a hypothesis in view of the fact that the disease often occurs in conditions where the spinal cord is quite healthy. In using the name "orthostatic purpura "it is not intended to make a fresh subdivision but merely to direct attention to this peculiarity. In 1881 it was suggested by Ceci of Prague that purpura might be caused by the action of an organism which he believed he had isolated, and which, when injected into the veins of animals, caused hæmorrhages. These statements have never been confirmed but micro-oroanisms have been found by one or two other observers. On the other hand, I have had all my cases examined systematically and the blood has in every case been found sterile. It is therefore fair to assume that organisms are not necessarily present and possibly when they have been found the result has been due to defective methods.

Birmingham.

\section{UNCOMPLICATED MYOCARDITIS IN A GIRL IN HER EIGHTH YEAR ASSO- CIATED WITH SIGNS OF CARDIAC FAILURE AND FOLLOWED BY SUDDEN DEATH. ${ }^{1}$}

BY GEORGE CARPENTER, M.D. LOND.,

PHYSICIAN TO THE EVELINA HOSPITAL FOR CHILDREN; ASSISTAN PHYSICIAN TO THE NORTH-EASTERN HOSPITAL FOR CHILDREN.

A GIRL, aged seven years and 11 months, was brought to the North-Eastern Hospital for Children on Jan. 11th, 1904. Her health had been quite good until July, 1903; at that time she had an ulcerated mouth and her breath was very offensive. Since August she had been an out-patient at the Adelaide Infirmary. She went to Sunday school on Jan. 10th but fainted while there and was carried home. There was history neither of diphtheria nor of rheumatism to be obtained. She had never had scarlet fever. When I saw her she was somewhat cyanosed. Her pulse was weak at the wrist and the first cardiac sound was not good. The second at the left base was accentuated. There was no extension of dulness to the right and there was no regurgitant pulse in the ressels of the neck. A few bronchitic signs were to be heard over the lungs and the free edge of the liver was felt two fingers' breadth below the costal margin in the nipple line. The patellar reflexes could not be obtained; the soft palate acted but not very freely. Her urine was nearly solid with albumin. I thought her to be suffering from myocarditis and admitted her into hospital. On the day of admission the highest pulse-rate was 136 to the minute and the highest respiration-rate was 48 to the minute. Nothing abnormal was detected in her fundus oculi. Her temperature was $97.8^{\circ} \mathrm{F}$. On the following day she was much worse. She was cyanosed; the breathing was shallow and irregular; the heart sounds were very faint

1 The specimens were exhibited at the Socicty for the Study of Disease in Children on Feb. 19th, 1904. and feeble and the pulse could not be felt at the wrist. She died at 3.30 P.M.

The post-mortem examination was made on the following day at 2.30 P.M. She was a well-nourished child ; rigor mortis was passing off. There were four ounces of serum in the abdominal cavity and one and a half ouncesin the pericardial sac. The heart weighed seven ounces. Its valves were healthy. The right side was slightly dilated; it was thinwalled, pale, and friable. The left ventricle was of normal thickness ; it also was very pale and friable. Both auricles were dilated and pale. The heart was pale on its endocardial surface as well as on its pericardial aspect. All its cavities were filled with blood clots. The extreme pallor of the heart was the most striking feature. The lungs were heavy and dropsical; the right weighed nine and a half ounces and the left seven and a half ounces. The liver was pale; its free edge was on a level with the costal margin in the nipple line. The right kidney weighed three and a half ounces and the left three ounces; they were pale. The spleen and pancreas were normal ; the former weighed one and a half ounces and the latter two ounces. The mucous membrane of the stomach was injected and it contained a little altered blood. The intestines were normal. The brain, which weighed $40 \frac{1}{2}$ ounces, was normal.

Mioroscopioal examination.-The heart muscle was stained by Marchi's method, which showed fatty degeneration of some of the muscle fibres of both ventricles and auricles. The straight tubules of the kidney contained a considerable number of red blood corpuscles. The corpuscles were shrivelled and old, they were widely distributed, and filled the lumen of many of the straight tubules, forming casts there. In addition the two-thirds of the kidney nearest the pelvis contained an amount of scattered pigment granules. These granules were not uniformly distributed, certain areas being quite free from them, while in other parts they were very numerous and closely aggregated. They varied in colour from golden yellow to nearly black. Some were incorporated with the cells of the tubules but others lay on their surface. In places their origin from the altered blood cells could be made out

Remarks.-In vol. iii. of the Reports of the Society for the Study of Disease in Children (pp. 170-81) and the paper which was read before the society and published in full in THE LANCET of May 30th, 1903, p. 1508, I drew attention in this country, under the heading of " Uncomplicated Myocarditis in Children," to the occasional occurrence of clinical examples of primary degeneration of the heart muscle in the young with all the symptoms of valvular disease and without endocarditis, of which the case whose history I have just narrated and from whom the specimens which I now show were taken is an excellent example. Long prior to this, in 1896, I had called attention to the condition in America. ${ }^{2}$ In my other cases, one, postdiphtheritic, whose cardiac symptoms were much like those of the child under discussion, recovered. Another of unknown causation died and interstitial myocarditis was found post mortem. A third, of rheumatic origin, died suddenly and fatty degeneration of the heart muscle was found. A fourth, a boy, aged 12 months, showed extensive fibroid disease of the heart. The child died suddenly and general tuberculosis was found at the necropsy. The cause of the heart disease was not obvious and possibly rheumatism was responsible. There was no evidence of syphilis. In the present example the cause for the fatty degeneration of the heart is not certain, but I am inclined to the view that it is post-diphtheritic; at least, that appears to me the most likely solution.

I claim for myocarditis, including in this term cases of fatty degeneration of the muscle fibres pure and simple, a distinct clinical entity. I have used the term myocarditis with intent and not because $I$ wish it to be understood that I consider there is anything about the condition of an inflammatory nature. For one reason it is customary at the present time in text-books on children's diseases to group such conditions under the heading myocarditis, but $I$ have used the term chiefly because I wish the case to appear as an addendum to my recent communication on myocarditis in children. The disorder in a pronounced case, in the absence of complaints known to produce it, can be diagnosed during life; and it is a state, dangerous though it be, from which recovery can and does take place, even in a severe case, as I have more than once observed. The incidence of cardiac symptoms in association with diphtheria, rhenmatism, or

2 Two Fatal Cases of Heart Disease in which the Cardiac Muscle was alone Involved, Pediatrics, vol. i1., pp. 234-38. 